\title{
Curvature of dendritic nonlinearities modulates higher-order spiking correlations
}

\author{
Alex Cayco-Gajic ${ }^{1 *}$, Joel Zylberberg ${ }^{2}$, Eric Shea-Brown ${ }^{2}$ \\ From 24th Annual Computational Neuroscience Meeting: CNS*2015 \\ Prague, Czech Republic. 18-23 July 2015
}

Characterizing neural spiking covariability is essential for understanding the collective activity of neural populations. Recent experiments have provided evidence of statistical dependencies among groups of neurons beyond that expected by the firing rates and pairwise correlations alone [1-3]. These "higher-order correlations" (HOCs) can be generated by common input [4] or motifs within the network architecture [5], yet a complete mechanistic understanding is lacking. We explore a novel mechanism through which higher-order correlations can be modulated: dendritic nonlinearities. We simulated the spiking activity of a simple exponential integrate-and-fire model neuron in response to two correlated presynaptic spike trains and background

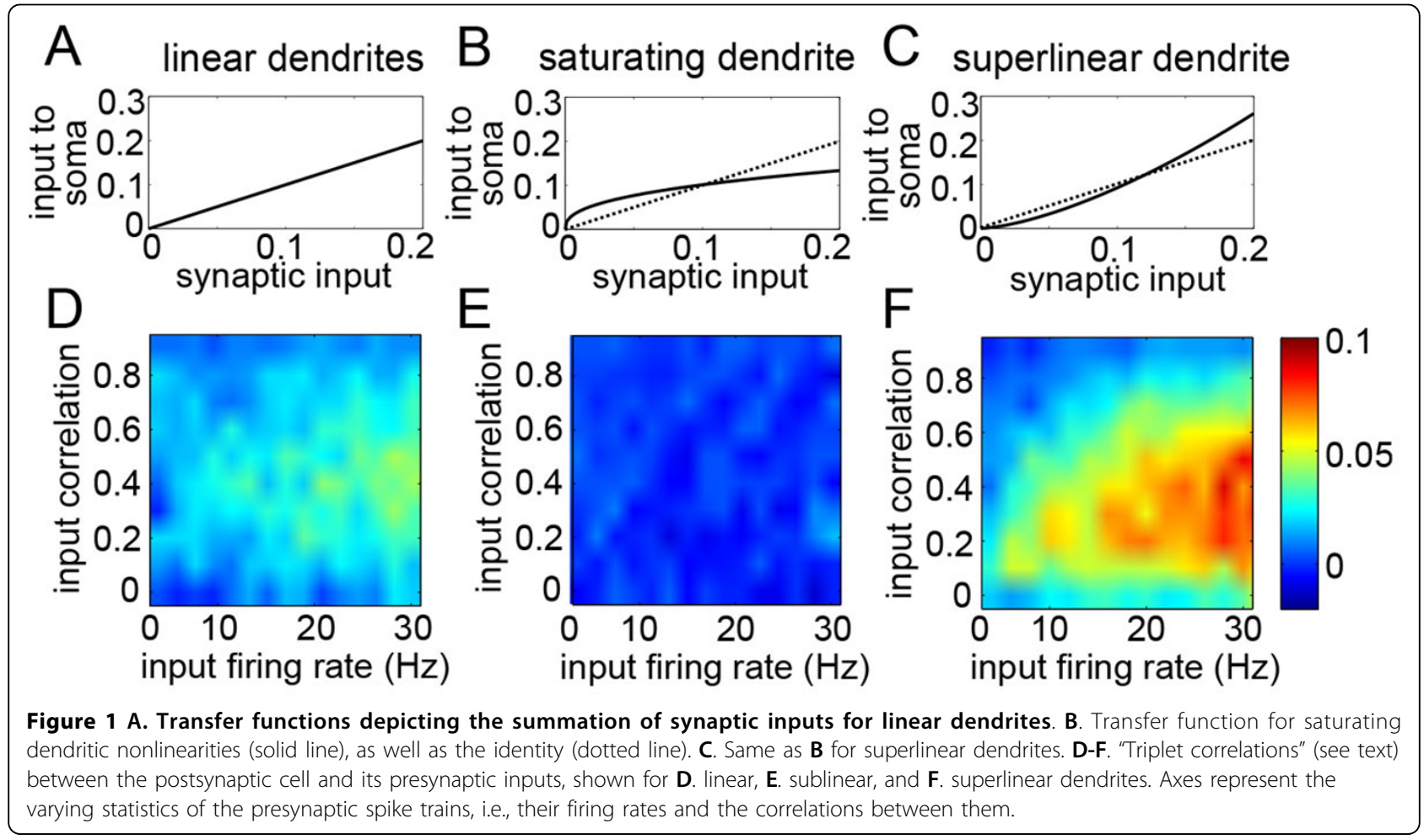

\footnotetext{
* Correspondence: natasha.gajic@ucl.ac.uk

'Department of Neuroscience, Physiology \& Pharmacology, University

College London, London, UK

Full list of author information is available at the end of the article
} 
noise. The synaptic conductances were either summed linearly at the soma or were filtered through a nonlinear dendritic transfer function (see Figure 1), which was chosen to have a similar magnitude of effect on nonlinear EPSP summation as observed by active dendritic properties in pyramidal cells [6]. Using maximum entropy techniques, "triplet correlations" in the circuit were quantified as the probability of synchronous triplet spiking between the postsynaptic cell and its two presynaptic inputs beyond what could be captured by the firing rates and pairwise correlations alone, normalized by the product of the standard deviations. We found that superlinear dendrites significantly increased the level of triplet. On the other hand, saturating dendrites decorrelated triplets. These results reveal that HOCs in spiking activity are modulated by the curvature of the dendritic transfer function. Finally, this study demonstrates how intrinsic single-cell properties can tune spiking covariability in neural populations.

\section{Authors' details}

'Department of Neuroscience, Physiology \& Pharmacology, University College London, London, UK. ${ }^{2}$ Department of Applied Mathematics,

University of Washington, Seattle, WA, USA.

Published: 18 December 2015

\section{References}

1. Ohiorhenuan IE, Mechler F, Purpura K, Schmid A, Hu Q, Victor JD: Sparse coding and high-order correlations in fine-scale cortical networks. Nature 2010, 466:617-621.

2. Ganmor E, Segev R, Schneidman E: Sparse low-order interaction network underlies a highly correlated and learnable neural population code. PNAS 2011, 108:9679-9684.

3. Koester U, Sohl-Dickstein J, Gray C, Olshausen B: Modeling higher-order correlations within cortical microcolumns. PLOS Comp Bio 2014, 10:1003684.

4. Macke J, Opper M, Bethge M: Common input explains higher-order correlations and entropy in a simple model of neural population activity. Phys Rev Lett 2011, 106.

5. Hu Y, Trousdale J, Josic K, Shea-Brown E: Local paths to global coherence: Cutting networks down to size. Phys Rev E 2014, 89:032802.

6. Polsky A, Mel B, Schiller J: Computational subunits in thin dendrites of pyramidal cells. Nature Neurosci 2004, 7:621-627.

doi:10.1186/1471-2202-16-S1-P227

Cite this article as: Cayco-Gajic et al: Curvature of dendritic nonlinearities modulates higher-order spiking correlations. BMC Neuroscience 2015 16(Suppl 1):P227.

\section{Submit your next manuscript to BioMed Central and take full advantage of:}

- Convenient online submission

- Thorough peer review

- No space constraints or color figure charges

- Immediate publication on acceptance

- Inclusion in PubMed, CAS, Scopus and Google Scholar

- Research which is freely available for redistribution

Submit your manuscript at www.biomedcentral.com/submit
C Biomed Central 